\title{
É POSSÍVEL UMA INICIAÇÃO CIENTÍFICA NO ENSINO MÉDIO COMO PROJETO PARA A DIVULGAÇÃO DA FÍSICA MODERNA E CONTEMPORÂNEA?
}

\author{
Adílio Jorge Marques ${ }^{1}$ \\ Cláudio Elias da Silva ${ }^{2}$
}

\section{RESUMO}

É possível trabalhar temas de Física Moderna e Contemporânea FMC, na escola de Ensino Médio? Esta proposta visa a trazer a experiência com um projeto paralelo que chamamos originalmente de "Monitoria de Pesquisa Discente", nos mesmos moldes da Iniciação Científica do Ensino Superior. A prática foi realizada no Colégio Santo Inácio RJ, durante os anos de 2004, 2005 e 2006. Desenvolvido extraclasse, o referido projeto mostrou funcionar também como facilitador para a disciplina, com abordagem de questões não discutidas amplamente em sala de aula, tais como: Astronomia; aspectos da Física Moderna; participação em olimpíadas nacionais; montagem eletrônica e experimentos diversos.

Palavras-Chave: FMC; Ensino de Ciências; Astronomia.

\section{ABSTRACT}

Is it possible to work themes of Modern and Contemporary Physics MCP (FMC in Portuguese) in the school of Medium Teaching? This proposal hope to bring the experience with a parallel project that we called originally "Research Monitored with Students", however, in the same molds of the Scientific Initiation of the Higher education. The practice was accomplished at the "Colégio Santo Inácio" - RJ, during the years of 2004, 2005 and 2006, developed extra-class, where it showed to work also as facilitator for the discipline, with approach of subjects no discussed thoroughly at classroom, such as: Astronomy; aspects of Modern Physics; participation in national Olympic Games; electronic assembly and several experiments.

Word-keys: FMC; Teaching of Sciences; Astronomy.

\section{INTRODUÇÃO}

Atualmente, ocorre um movimento de maior interesse pela pesquisa em Física Moderna e Contemporânea (FMC) inserida na grade curricular do Ensino Médio. Muitos livros didáticos vêm trazendo em seu conteúdo comentários, partes ou capítulos dedicados ao assunto, porém normalmente destacados do contexto do restante da obra e mesmo da realidade brasileira. A proposta da introdução da FMC no Ensino Médio, através de projetos paralelos, é uma alternativa a ser considerada, seja através do estudo de um único tema em projetos específicos ou mesmo de vários tópicos da FMC, quando se tratar de um projeto pensado para ocorrer durante todo o ano letivo. No caso da experiência aqui relatada, começou como uma proposta para dois meses em relação à Astronomia, mas que se estendeu por mais cinco meses devido à existência de um projeto paralelo desenvolvido no Colégio, chamado "Monitoria de Pesquisa Discente".

Vemos que a atual legislação educacional brasileira incentiva o ensino de novas tecnologias e conteúdos, deixando livre às escolas a adaptação curricular e a decisão de quais competências e habilidades em Física os alunos devem adquirir. Sabemos que a quebra de paradigmas educacionais muitas vezes é lenta, enfrentando a oposição de setores da própria educação. A ideia é que acontecimentos ou projetos, como a Olimpíada Brasileira de Astronomia e Astronáutica (OBA), podem e devem ser utilizados de muitas maneiras, já que, atualmente, como recurso pedagógico, infelizmente, são pouco explorados. Fora do Brasil, tais aproveitamentos existem há muitos anos.

A motivação discente pode começar também pelo processo de alfabetização científica, sendo que esta deve ser separada do conhecimento adquirido pelo senso comum. O interesse pela FMC no Colégio Santo Inácio intensificou-se através de uma amostra sobre astronomia. As relações de causa e efeito

${ }^{1}$ Doutor em História e Epistemologia das Ciências pela UFRJ, Professor de Física no Colégio Santo Inácio RJ e da Secretaria Estadual de Educação do RJ. ${ }^{2}$ Doutor em Geofísica pelo Observatório Nacional, Professor Adjunto da Universidade do Estado do Rio de Janeiro. 
facilitam para muitos o mecanismo do aprendizado. Porém, dentro da realidade do ensino, nem sempre é possível uma experiência prática de todos os temas estudados, o que não deve impedir a inclusão de qualquer assunto, contanto que haja uma motivação.

Podemos, então, fazer da OBA uma destas motivações discentes? E, por que não, promover um salto cognitivo do próprio educador? As exposições realizadas em nosso projeto foram conceituais e sem a preocupação matemática inerente a muitos livros didáticos ou mesmo como encontrado normalmente na Internet. A proposta era fazer um aprofundamento conceitual da FMC através da astronomia.Em muitos Estados do Brasil, a FMC não é cobrada nos vestibulares, o que faz com que não seja incluída no planejamento da Física nas escolas dessas localidades. O aluno sente-se muitas vezes desorientado, pois a sua realidade (e a mídia) reflete um universo que é permeado de tecnologias e descobertas que necessitam ao menos tangenciar, senão aprofundar, o conhecimento em FMC. Ao mesmo tempo, os docentes não têm mais a oportunidade de exercitar o que aprenderam na Universidade, acabam muitas vezes ficando "engessados" em uma ementa que se volta à aprovação em determinadas provas de concurso.

Pensando neste quadro, elaboramos um projeto em Física que pudesse propiciar ao aluno do Colégio um espaço fora da sala de aula, com maior liberdade para o Professor Orientador buscar novos temas a serem pesquisados e discutidos. Um projeto que levasse o aluno participante ao estudo, mas que o motivasse a ver a Física com outros olhos, de maneira diferente das fórmulas matemáticas decoradas dos livros didáticos e dos vestibulares.

\section{DESCRIÇÃO DO PROJETO}

O passo primeiro, após a aprovação da Direção, foi o de receber as inscrições dos alunos por escrito, após carta enviada aos responsáveis. A cada ano, ficha de inscrição, normas, relatório final, fichas de acompanhamento foram criadas para apresentar o projeto ao Colégio e à comunidade escolar. Participaram alunos da $8^{\mathrm{a}}$ série do Ensino Fundamental a $3^{\mathrm{a}}$ série do Ensino Médio. Não foi o caso nestes dois anos de funcionamento, mas a participação de alunos da $8^{\mathrm{a}}$ série, se em número maior que os de Ensino Médio, irá condicionar neste projeto a uma adaptação, adequando o nível das apresentações a esta série, ou mesmo na criação de classes de Iniciação Científica separadas.
Escolhemos sempre um dia da semana, em horário diferente do horário de aulas dos alunos, no nosso caso, à tarde. Ressaltamos que durante as semanas de provas, como acontecem neste Colégio, em particular, os projetos em geral são suspensos para permitir ao aluno total concentração nas mesmas. Todos os alunos que tiveram um mínimo de $75 \%$ de frequência e bom aproveitamento no projeto receberam um certificado de participação. Uma pequena solenidade de entrega é organizada quando possível, assim como acontece com a entrega dos certificados e medalhas aos participantes das Olimpíadas estudantis de Física e Astronomia. Tal cerimônia é uma sugestão do Comitê Organizador da própria Olimpíada Brasileira de Astronomia, que adotamos para o nosso projeto.

Realizamos sempre uma aula inaugural no intuito de chamar a atenção dos alunos para o lúdico e a parte prática da Física. Neste evento, realiza-se uma série de experiências físicas com equipamentos do próprio Laboratório de Física do Colégio e com montagens, utilizando material alternativo (garrafas pet, isopor, latas de alumínio, etc.) de outros projetos mais antigos. Consideramos a aula inaugural fundamental para que o aluno possa conhecer o projeto e se ambientar com a proposta e as normas, principalmente os mais jovens. $\mathrm{Na}$ aula inaugural, explicamos que é obrigatória a participação dos alunos deste projeto em qualquer evento relacionado à Física onde o Colégio esteja envolvido, como é o caso das Olimpíadas.

\section{IMPORTANTE: AS OLIMPÍADAS DE ASTRONOMIA/ASTRONÁUTICA E DE FÍSICA}

No primeiro semestre de cada ano, utilizamos as semanas seguintes a esta aula preparando também o grupo de Monitores para participar da Olimpíada Brasileira de Astronomia e Astronáutica (OBA) e, posteriormente, no semestre seguinte, da Olimpíada Brasileira de Física (OBF). Para o estudo de temas de Astronomia, partimos de questões e resultados [2] das provas anteriores da própria OBA [10], além da curiosidade que os alunos manifestavam nas discussões promovidas a partir da segunda semana do projeto. Salientamos que dúvidas sobre os temas astronômicos são muito recorrentes. Verifica-se que a Astronomia é um tema muito facilmente colocado pela mídia em geral, e muitas dúvidas [3], básicas ou não, surgem constantemente em sala de aula ou em debates com os alunos, com questões sempre as mais 
diversas, independentemente do meio cultural.

Destacamos, fora de ordem, os temas para debates e seminários teóricos no projeto:

- A atração gravitacional;

- Os trabalhos de Isaac Newton;

- O começo do universo;

- Formação planetária;

- O que são e como se formam as estrelas, planetas e os elementos químicos;

- Os cometas;

- Os buracos negros;

- As galáxias e a Via Láctea;

- O Sol.

Como apresenta-los? Através de vídeos, internet, de exposições do Professor Orientador, mais tarde dos próprios alunos, através de seminários, palestras realizadas no Colégio com professores convidados. Buscamos, neste bimestre inicial, estudar e discutir os temas acima listados, conseguindo uma participação crescente de alunos do nosso Colégio na prova da OBA: em 2003, antes da Monitoria, participaram dois alunos do Ensino Médio; em 2004, após as primeiras semanas do projeto, um total de 24 alunos (um aluno da $4^{\text {a }}$ série do Ensino Fundamental e os demais do Ensino Médio). Desse total, três medalhas foram conquistadas. E, em 2005, nada menos que 345 alunos de todo o Colégio participaram da OBA, motivados que foram pela divulgação do projeto e do que esta olimpíada representa, com vários medalhistas, inclusive de ouro.

A participação na Olimpíada de Física também aumentou: de dois alunos, em 2003, para 14, em 2004. Esta prova abrange conhecimentos mais pertinentes à Física Clássica, servindo para nosso projeto como instrumento de medida do conhecimento na área e do interesse geral dos alunos. Em 2005, foram mais de 200 participantes na primeira fase, quando conseguimos por esta Olimpíada como parte do planejamento da área de Física. Como parte do projeto, realizamos uma ou mais visitas dos alunos ao Laboratório divulgação de Física da Pontifícia Universidade Católica do RJ, chamado PIUES (Programa de Integração Universidade, Escola e Sociedade), e que se destina a aproximar os alunos de escolas públicas e particulares da Universidade, com o desenvolvimento de variados experimentos da Física, abrangendo o estudo de mecânica, óptica, eletricidade, etc. Os Monitores tiveram que realizar relatórios sobre a visita e tentar reproduzir as experiências no Colégio durante o ano na Monitoria.

Acreditamos que a aproximação dos alunos com a realidade universitária, com professores da área de Física, novos laboratórios e experimentos, faça aumentar o interesse, participação e surgimento de novas idéias para qualquer projeto.

\section{AFMC}

Com a estrutura do projeto apresentada, podemos mostrar como incluímos a FMC na dinâmica do colégio e da vida dos Monitores. $\mathrm{Na}$ verdade, a FMC vem como consequência natural de temas não comumente discutidos em sala de aula, mas que fazem parte da realidade de muitos. Inicialmente, enfatizamos mais uma vez a utilização e a discussão da OBA como introdução aos temas de FMC, por propiciar, em nossa opinião, o estudo e entendimento de uma matéria a Astronomia que não é disponibilizada nos currículos escolares de Ensino Médio, mas que, por outro lado, como mencionamos antes, está constantemente na mídia [5]. Também porque se pode estudá-la com enfoques variados, desde o mais teórico até o mais matemático, facilitando a adaptação ao tipo de situação e de alunos com que se trabalha.

Também através de vídeos, sites, seminários do Professor Orientador, e depois seminários realizados pelos próprios alunos, fomos discutindo e apresentando temas de FMC ao grupo no horário do projeto. E, após a prova da OBA, seguimos com os estudos teóricos sobre a FMC até o mês de novembro. Houve, nos dois anos deste projeto, seminários e debates sobre (fora de sequência):

- Espectro eletromagnético e luz visível [11];

-Corpo negro [4];

-Tipos de radiações;

-Efeito fotoelétrico;

-Conceitos e discussões iniciais sobre a relatividade especial e geral [8];

-Princípios da Física nuclear [4].

Tais temas se somam aos de Astronomia do início do ano, permitindo correlacionar os conhecimentos, mesmo que de forma introdutória. 
No $4^{\mathrm{o}}$ bimestre de 2004, os Monitores construíram, paralelamente, um emissor de infravermelho e um pequeno rádio, seguindo as orientações e os esquemas da referência [9]. Os alunos que participaram aprenderam sobre alguns componentes eletrônicos, também como soldar e qual a participação da Física na tecnologia atual. Em 2005, vimos teoricamente como funcionam alguns dos componentes eletrônicos mais usados atualmente.

\section{CONCLUSÕES}

Ao final de cada ano (2004/2005/2006), analisamos em conjunto, Professor Orientador e alunos, os resultados pedagógicos do projeto. $\mathrm{E}$ podemos responder à pergunta do título deste trabalho de forma positiva. Destacamos os seguintes pontos, que consideramos os mais importantes, observados no projeto:

-Desenvolvemos muitos temas, mas dependendo do perfil discente, pode-se experimentar uma maior concentração de temas durante o ano;

- Verificamos que a motivação é fundamental à participação de alunos em qualquer projeto educacional ou de divulgação da ciência. Através da Física, conseguimos aproximar os novos alunos com os mais antigos, através de um espaço democrático de discussão sobre a Física e aspectos tecnológicos. Um melhor relacionamento entre alunos mais tímidos e o Professor também foi observado [6];

- Um maior senso de responsabilidade foi adquirido pelos alunos, segundo palavras finais dos mesmos, pois trabalharam no Laboratório de Física do Colégio e se tornam responsáveis pelo material, todos identificados por crachá;

- Alguns alunos declararam que passaram a ter mais facilidade com a disciplina em sala de aula, pois viam a Física de maneira mais qualitativa e não apenas quantitativamente, ou seja, passaram a vê-la como uma forma de explicar a natureza através de conceitos bem distintos aplicáveis ao dia a dia. Comprovou-se a melhora nas notas destes alunos monitores durante os bimestres. Muitos alunos ofereceram certa resistência inicial para participar, pois se achavam incapazes de estudar ou desenvolver atividades em uma ciência exata, e ainda mais de executá-la em uma prática ou em seminários. Todos que permaneceram até o fim do projeto concluíram que, em conjunto, foi mais fácil trabalhar, e que é possível estudar Física "sem traumas", inclusive temas totalmente novos [1].

Gostaríamos de destacar a importância da Olimpíada Brasileira de Astronomia e Astronáutica como impulsionadora e motivadora destes projetos. A Astronomia foi o tema que permitiu a abordagem de vários outros aspectos pouco discutidos no Ensino Médio, como a Força de Coriolis e seus efeitos na Terra [10]. Também foi uma maneira de divulgarmos posteriormente a OBF, sendo esta uma outra oportunidade que os alunos tiveram para medir seus conhecimentos em Física até aquele momento. Com isso, destacamos a importância que a OBA pode desempenhar na estrutura de ensino da Física, além da difusão da ciência e da Astronomia em particular. Também foi possível relacionar temas das provas da OBA com a FMC estudada a partir do segundo bimestre.

Também é possível desenvolver projetos paralelos em escolas de Ensino Fundamental e Médio que propiciem atividades teóricas e algumas práticas de temas ligados a FMC sem comprometer o andamento curricular ou a preparação para o vestibular. Contrariamente à alegada falta de tempo, achamos que um espaço a mais de estudo e trabalho com temas diferentes só poderá acrescer ao aluno, pois muitos vestibulares atualmente já cobram a FMC em suas questões. Sugerimos que o estudo da FMC no Ensino Médio pode ser viável através de projetos paralelos, ocorridos em outro momento dentro das escolas que não no horário regular. $\mathrm{O}$ projeto aqui descrito contou com dois tempos de 50 minutos por semana nos dois anos em que se realizou.

A abertura de muitos horários diferentes pode não ser interessante, ao contrário do que parece, pois uma dispersão dos alunos reduz a interação entre eles. Por isso, começamos em 2004 com três horários diferentes à tarde, e depois reduzimos para dois. No ano de 2005, oferecemos apenas um horário semanal.

Particularmente, em nosso caso, utilizar a Iniciação Científica como auxílio didático de bons alunos a colegas com dificuldades em Física não correspondeu aos resultados comumente esperados. Poucos alunos em dificuldades procuraram os Monitores, apesar da montagem de uma grade horária com a disponibilidade para tirar dúvidas no ano de 2004. Acreditamos, porém, que isso também pode variar de acordo com o perfil de cada escola.

Apesar de ajudar bastante, ressaltamos que não é indispensável ter um Laboratório de Física na 
escola para a realização do projeto, como em nosso caso. A utilização de uma sala só para tal uso e a utilização de materiais alternativos podem suprir em muito ou mesmo totalmente o que foi descrito como construção e prática. O uso de vídeos, ou de um canal fechado de ciências, certamente ilustraria melhor as aulas do(s) Professor(es) Orientador(es) do projeto. A disponibilidade de um computador de médio porte, ligado à internet, e uma pequena biblioteca com livros de Física e Astronomia ajudarão sobremaneira. O Professor deverá auxiliar os alunos no melhor material a ser discutido de acordo com o planejamento adotado para o projeto e o tempo disponível.

\section{SUGESTÕES DO PROJETO PARA A DIVULGAÇÃO DAFMC}

Sugere-se que os Colégios que trabalham com o estudo e prática da robótica possam unir tal projeto com o aqui apresentado de Monitoria e Pesquisa em Física na construção de eletrônicos, como os utilizados na referência [2]. Outros projetos, unindo a Física e as várias aplicações tecnológicas modernas, poderiam ser experimentados futuramente, envolvendo a construção e manuseio de eletrônicos.

Criamos, em 2004, o “Jornal da Física”, que é um excelente divulgador das idéias dos alunos na comunidade escolar. A reprodução ocorreu através de xerox e cada edição veio presa às provas bimestrais, o que não acarretou grande custo. Em 2004, era composto apenas de uma folha tamanho A4 frente e verso, tornando-o mais viável. Em 2005, deixamos de usar o programa "Word" e passamos a utilizar o "Publisher", passando o jornal a ter um novo estilo de apresentação e com duas páginas, também em frente e verso, distribuído da mesma forma.

Como consequência do Jornal da Física aqui apresentado, sugerimos a construção do mesmo em forma eletrônica nas escolas que possuam site, sendo o Jornal um link dentro do mesmo.

Outra possibilidade é a criação de um blog de Física associado à Iniciação Científica, com a supervisão do Professor(es) da área, permitindo uma rápida interação entre os alunos da escola e os participantes dos projetos. O blog também seria um facilitador ao Professor de Física que quisesse uma maior interação com os alunos de sua classe.

\section{REFERÊNCIAS}

[1] ALVES, V. C.; O Lúdico como ferramenta no ensino de Física; Atas do XV Simpósio Nacional de Ensino de Física; pág. 992-1002; 2003.

[2] CANALlE, J. B. G et all; Resultados da III Olimpíada Brasileira de Astronomia; v. 3; n. 2; p. 11$16 ; 2002$.

[3] CANALLE, J. B. G.; O problema do ensino da órbita da Terra; Física na Escola; v. 4; n. 2; p. 12-16; 2003.

[4] JÚNIOR, D. B.; Física Moderna; Ed. Companhia da Escola; $1^{\mathrm{a}}$ edição; 118p.; 2002.

[5] MARQUES, A. J., da SILVA, C. E.; Utilização da Olimpíada Brasileira de Astronomia como Introdução à Física Moderna no Ensino Médio; Física na Escola; v. 6; n. 2; 2005.

[6] MENEZES, L. C.; Uma Física para o novo Ensino Médio; Física na Escola; v. 1; n. 1; p. 6-8; 2000.

[7] OSTERMANN, F.; Um texto para professores do Ensino Médio sobre partículas elementares; Revista Brasileira de Ensino de Física; vol. 21, n. 3; p. 415436; 1999.

[8] OSTERMANN, F., RICCI, T. F.; Relatividade Restrita no Ensino Médio: contração de LorentzFitzgerald e aparência visual de objetos relativísticos em livros didáticos de Física; Cad. Bras. Ens. Fís.; v. 19, n. 2; p. 176-190; 2002.

[9] TAVOLARO, C. R. C., CAVALCANTE, M. A.; Física Moderna Experimental; Ed. Manole; $1^{\mathrm{a}}$ edição; 119 p.; 2003.

[10] http://www.oba.org.br/; Brasil.

[11] http://astro.if.ufrgs.br/rad/espec/espec.htm 